\title{
Role of nutrition support in adult cardiac surgery: a consensus statement from an International Multidisciplinary Expert Group on Nutrition in Cardiac Surgery
}

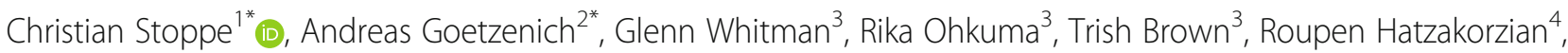 \\ Arnold Kristof ${ }^{5}$, Patrick Meybohm ${ }^{6}$, Jefferey Mechanick ${ }^{7}$ Adam Evans ${ }^{8}$, Daniel Yeh ${ }^{9}$, Bernard McDonald ${ }^{10}$, \\ Michael Chourdakis ${ }^{11}$, Philip Jones ${ }^{12}$, Richard Barton ${ }^{13}$, Ravi Tripathi ${ }^{14}$, Gunnar Elke ${ }^{15}$, Oliver Liakopoulos ${ }^{16}$, \\ Ravi Agarwala ${ }^{17}$, Vladimir Lomivorotov ${ }^{18}$, Ekaterina Nesterova ${ }^{19}$, Gernot Marx $^{1}$, Carina Benstoem², \\ Margot Lemieux ${ }^{20}$ and Daren K. Heyland ${ }^{20}$
}

\begin{abstract}
Nutrition support is a necessary therapy for critically ill cardiac surgery patients. However, conclusive evidence for this population, consisting of well-conducted clinical trials is lacking. To clarify optimal strategies to improve outcomes, an international multidisciplinary group of 25 experts from different clinical specialties from Germany, Canada, Greece, USA and Russia discussed potential approaches to identify patients who may benefit from nutrition support, when best to initiate nutrition support, and the potential use of pharmaco-nutrition to modulate the inflammatory response to cardiopulmonary bypass. Despite conspicuous knowledge and evidence gaps, a rational nutritional support therapy is presented to benefit patients undergoing cardiac surgery.
\end{abstract}

Keywords: High-risk cardiac surgery, Cardiopulmonary bypass, Systemic inflammatory response, Organ dysfunctions, Nutrition risk stratification, Underfeeding, Postoperative nutritional management, Supplemental parenteral nutrition, Enteral nutrition, Pharmaco-nutrition

\section{The scientific rationale for nutrition therapy in the cardiac surgery ICU}

Patients undergoing cardiac surgery are routinely exposed to significant systemic inflammation, causing organ injury and dysfunction. Cardiopulmonary bypass (CPB) triggers systemic inflammatory response syndrome (SIRS) with release of reactive oxygen species (ROS) and reactive nitrogen species (RNS) and mainly pro-inflammatory cytokines [1-3]. This often results in serious life-threatening complications with loss of physical capacity, associated with prolonged critical illness, which may negate any benefit from correction of the

\footnotetext{
* Correspondence: christian.stoppe@gmail.com; agoetzenich@ukaachen.de ${ }^{1}$ Department of Intensive Care Medicine, University Hospital of the RWTH Aachen, Pauwelsstraße 30, 52074 Aachen, Germany

2Department of Thoracic, Cardiac and Vascular Surgery, University Hospital, RWTH Aachen, Pauwelsstraße 30, 52074 Aachen, Germany

Full list of author information is available at the end of the article
}

original, underlying cardiac disease. Such patients require aggressive, life-sustaining therapies to promote organ recovery and mid to long-term outcome advantages [4].

Underfeeding is a major issue in cardiac surgery patients [5, 6]. Table 1 demonstrates an overview of clinical studies investigating nutritional support in patients undergoing cardiac surgery. No sufficiently designed, adequately powered, randomized controlled trials investigating the effect of nutritional therapy initiated early in high-risk cardiac patients after surgery are available. Yet, several small studies have provided initial evidence on the feasibility and clinical significance of nutritional therapy in cardiac surgery patients. We therefore aimed to develop an expert-derived consensus on best nutritional practices in this patient population. 


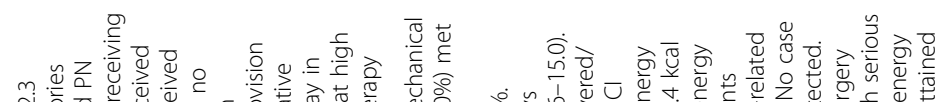

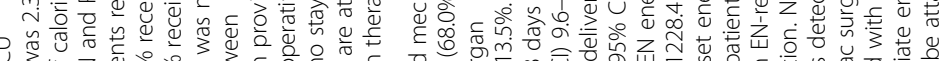

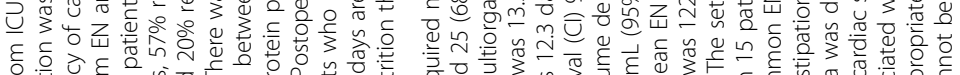

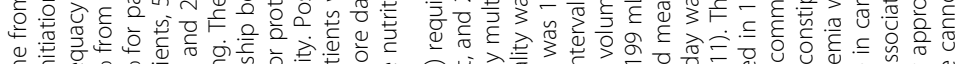

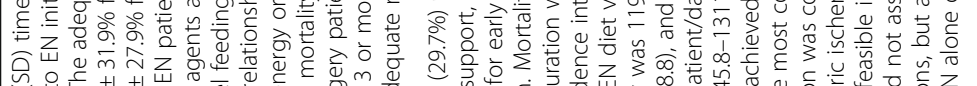

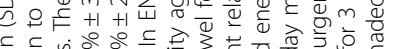

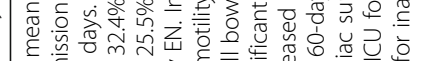

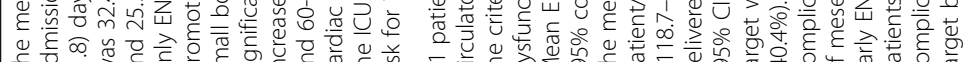

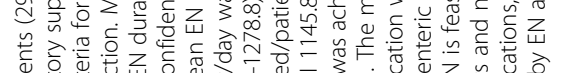

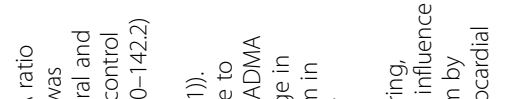

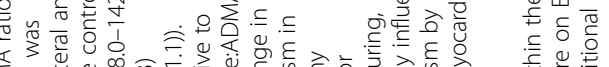

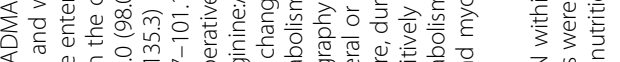

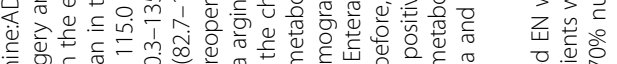

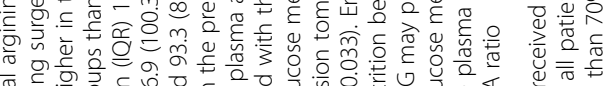

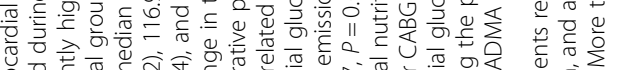

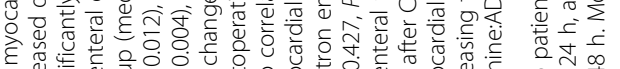

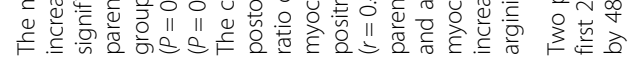

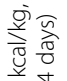 \\ 离 \\ प्र

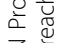 \\ 플}

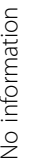

है
$\frac{7}{0}$
잉

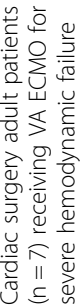

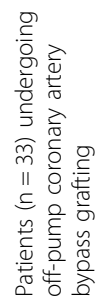

๕ั

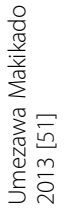




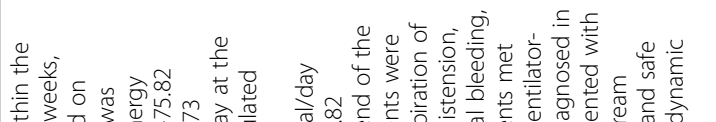

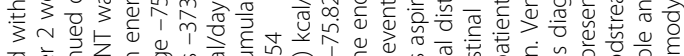

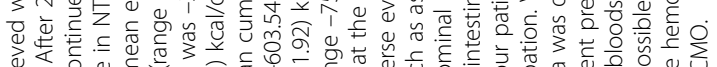

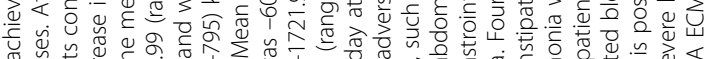

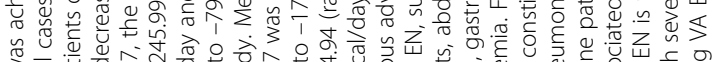

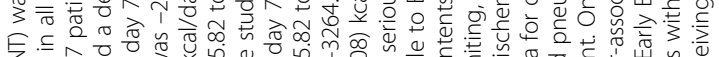

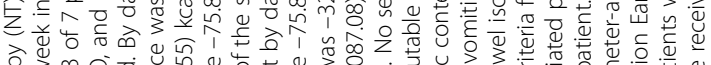

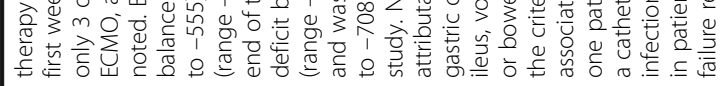
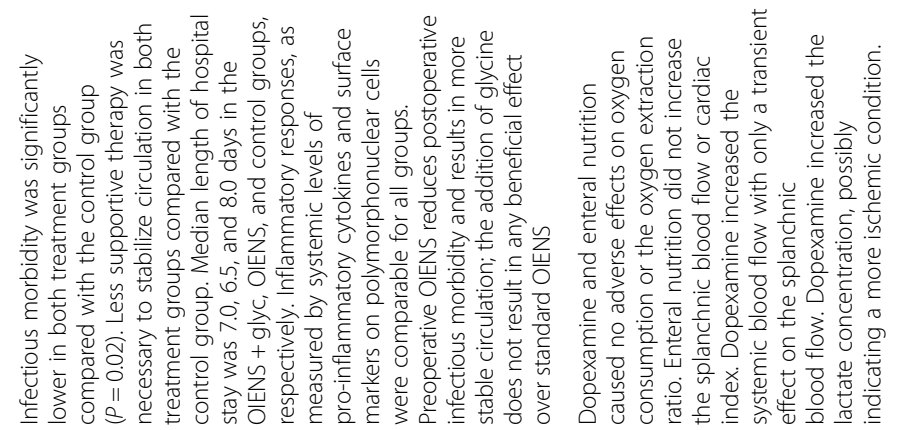

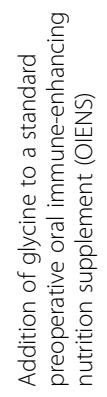

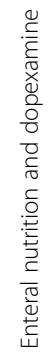

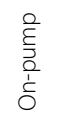

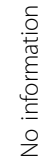

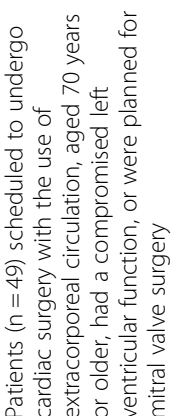

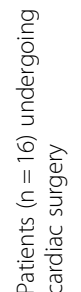

$\underset{x}{t}$

$\underset{x}{t}$

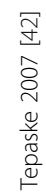

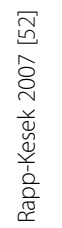



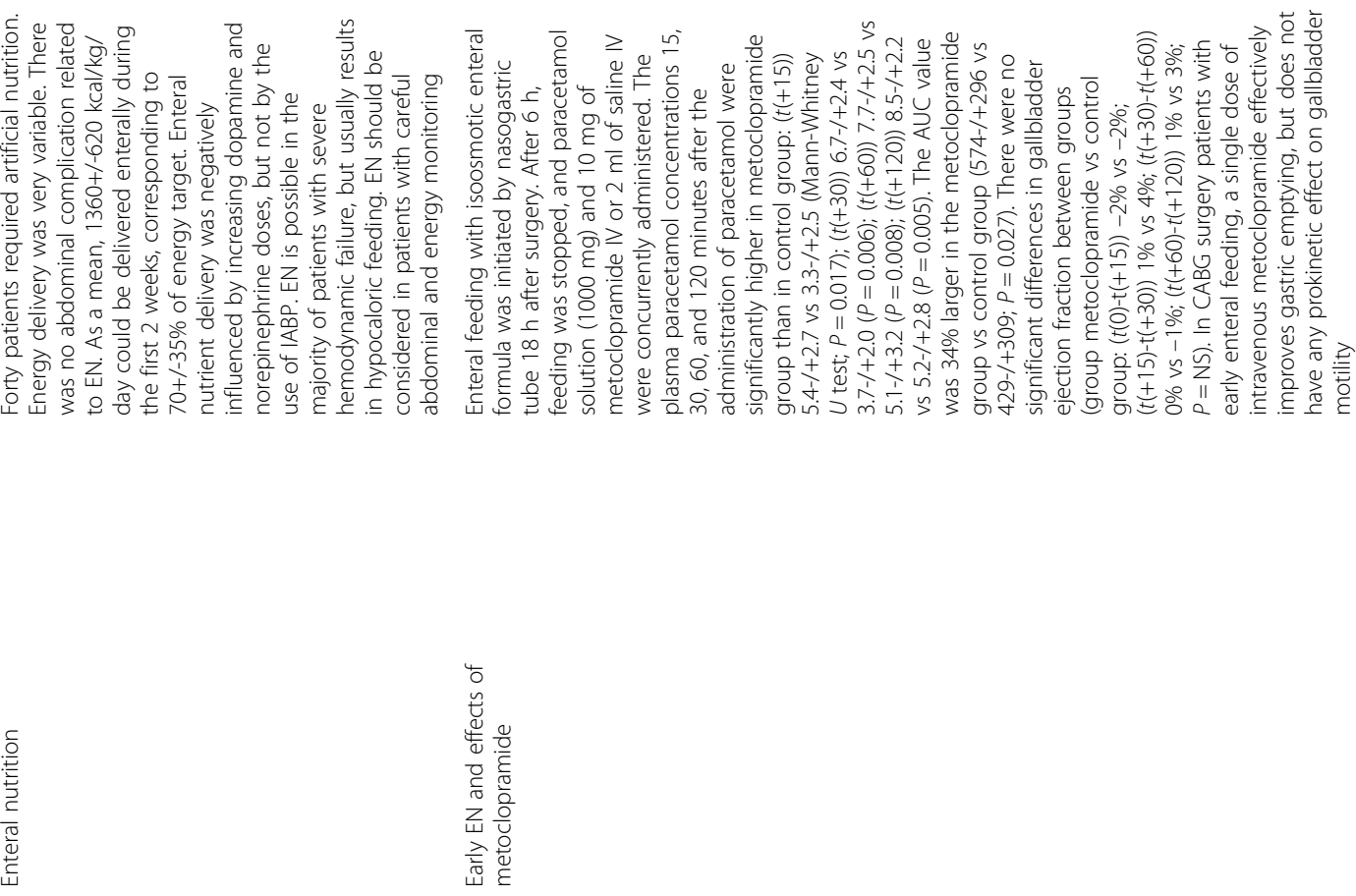


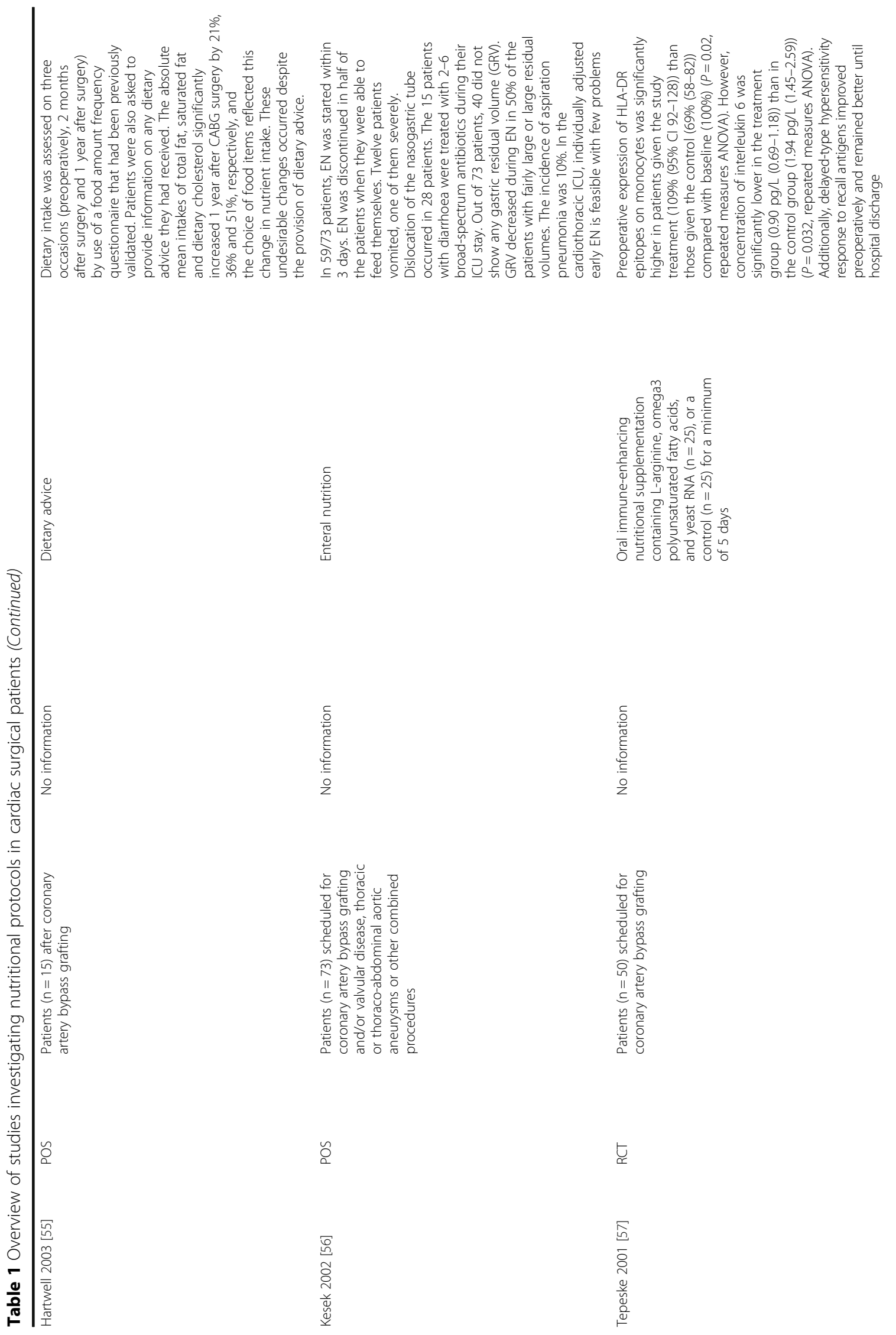




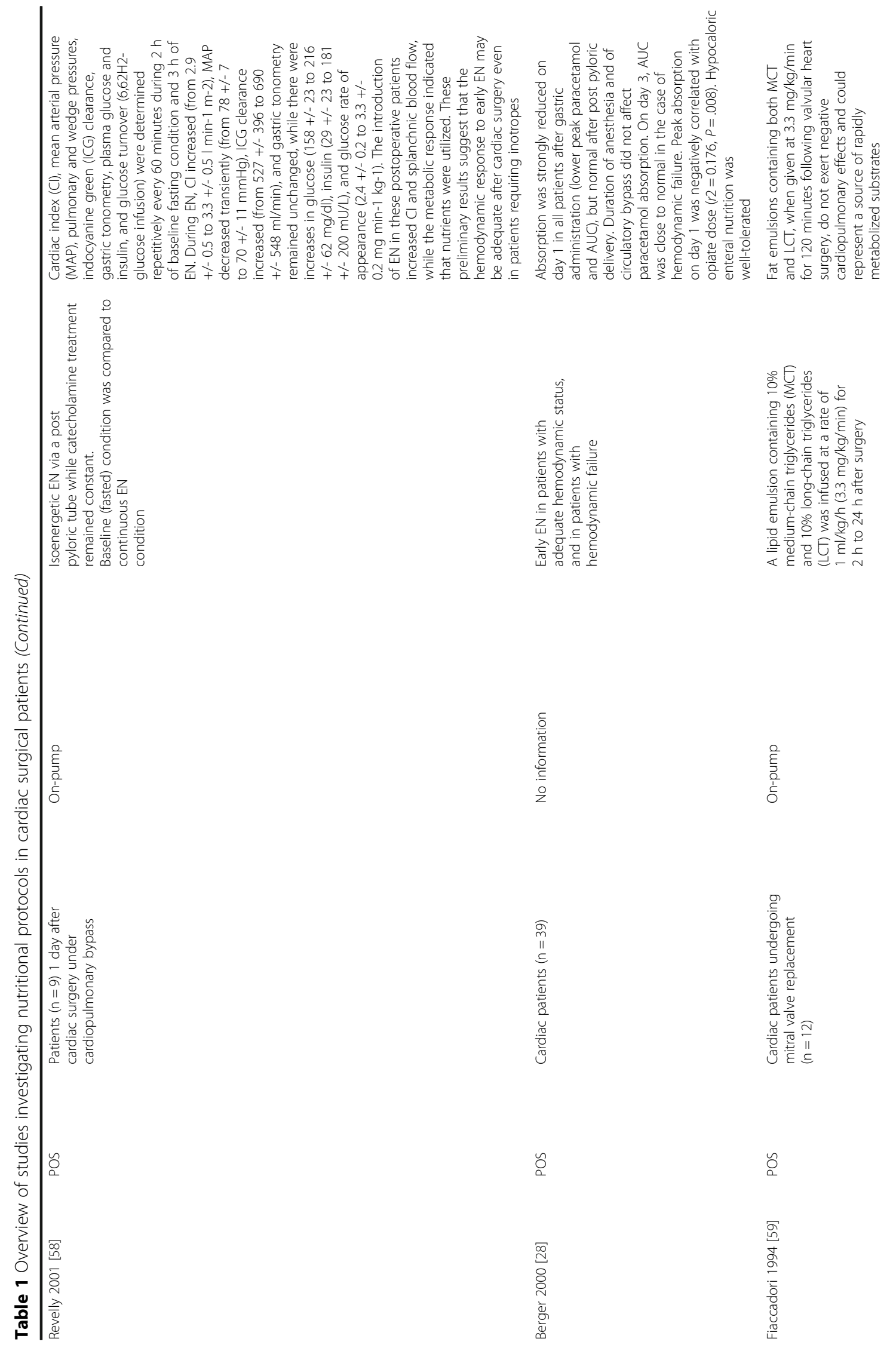




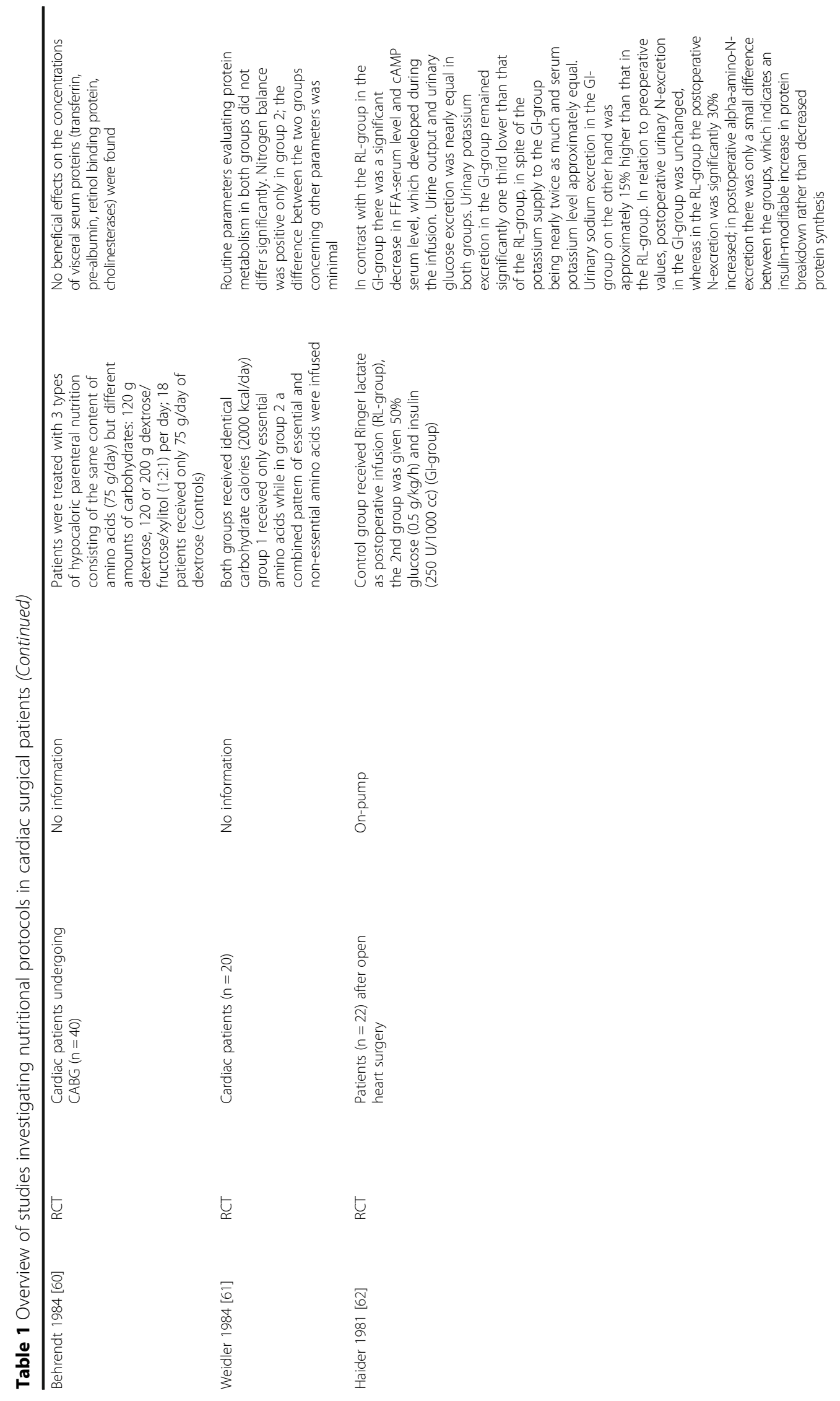




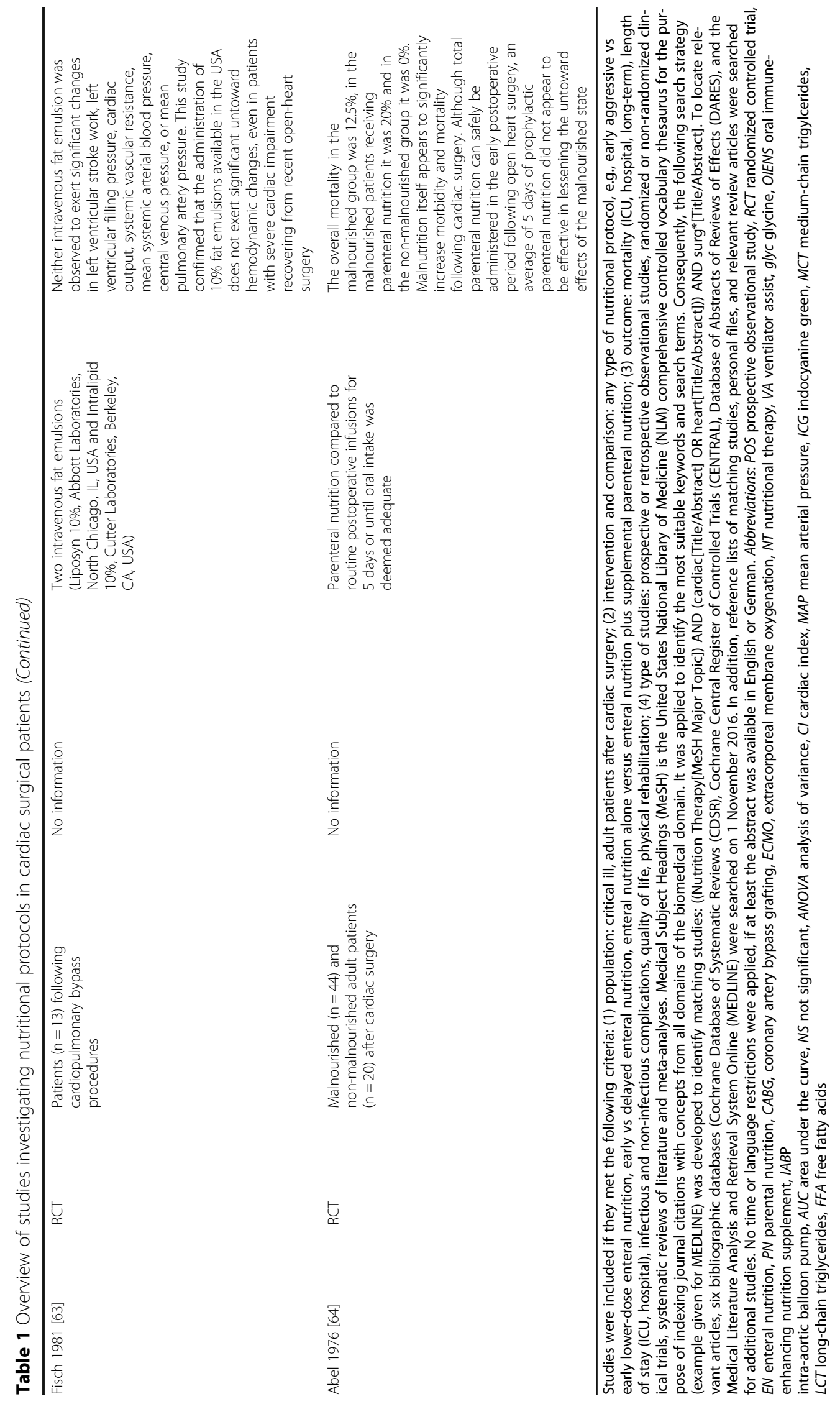




\section{Nutrition in cardiac surgery patients}

Preoperative fasting sets the stage for catabolic stress [7], insulin resistance [8], nutrient deficiencies, and adverse immune function [9]. During cardiac surgery, patients commonly receive only intravenous crystalloid solutions, which are continued for several days postoperatively [9].

Considering the postoperative course, in a retrospective analysis of about 5400 mechanically ventilated patients, cardiac surgery was most associated with iatrogenic malnutrition [5]. This alarming finding is compounded by observations that nutrition support was implemented later and with the lowest nutritional adequacy in the cardiac surgery population compared to all other surgical or medical ICU patients [5]. Recently, Rahman et al. [6] evaluated nutrition practices in cardiac surgery patients and demonstrated that nutrition support was insufficient with respect to energy and protein needs. Patients only received approximately $50 \%$ of what was prescribed. Importantly, an improvement in 60-day mortality with greater nutrition intake could not be demonstrated. This observation raises the question whether all cardiac surgery patients benefit the same from artificial nutrition therapy or whether there are specific subgroups of cardiac surgery patients that will benefit more.

As society ages, older patients are presenting for cardiac surgery with an increased prevalence of comorbidities. In addition, the number of patients with advanced heart failure has increased and the implantation of pulsatile-flow ventricular assist devices (VAD) has become an established therapeutic strategy to improve survival rates and quality of life [10]. Malnutrition may be a significant comorbidity and driver for dysfunction of many organ systems. This can exacerbate an already impaired organ reserve, increasing susceptibility to operative trauma, ischemia/reperfusion injury, anesthesiarelated complications, and inflammation. Cardiac patients who are well-nourished prior to surgery experience less morbidity and mortality than those who are malnourished $[11,12]$. Several observational studies have noted the importance of energy and protein metabolism in the early recovery period after cardiac surgery, documenting significant postoperative depletion of macronutrients and micronutrients [11-14]. Adequate nutritional therapy was suggested to improve patients' outcomes through maintenance of energy metabolism, gut integrity, microbial diversity and improved wound healing [15]. In summary, preoperative nutritional status and postoperative nutritional management may represent important drivers for clinical outcomes in patients undergoing cardiac surgery, who are at high nutritional risk, which will be discussed in the following section.

Figure 1 demonstrates selected key factors, which are considered to crucially influence the nutritional state and potential need for intense nutrition therapy in cardiac surgery patients.

\section{Nutrition risk stratification in cardiac surgery patients}

Selection of patients who will benefit most from nutrition support in the postoperative period is critical, but has not been established or standardized. When developed, this selection process would be based on a combination of clinical and biochemical parameters related to validated risk scores for nutrition, cardiac surgery, critical illness, and emerging markers of systemic inflammation, particularly those related to cardiopulmonary bypass and postoperative ICU pharmacology and technology.

\section{Preoperative nutrition risk assessment}

Several scores or assessment tools have been introduced to enable the quantification of nutrition risk. These tools were neither developed for nor validated in critically ill patients [16]. Therefore, the measurement of a patient's current nutritional status predominantly identifies those who have already reached an undernourished general state. To foresee an aggravation in the nutritional status, an assessment of nutritional risk must also identify patients at a pre-critical level of malnutrition, who will benefit (and not be harmed) by nutrition support. The Malnutrition Universal Screening Tool (MUST), the Mini Nutritional Assessment (MNA), the Short Nutritional Assessment Questionnaire (SNAQ), the Malnutrition Screening Tool (MST), and the Subjective Global Assessment (SGA) [16] are well-established assessment tools used to evaluate nutrition status in clinical practice.

Lomivorotov and colleagues demonstrated that in patients undergoing cardiac surgery, detection of malnutrition is associated with prolonged ICU stay ( $>2$ days) and both MUST and MNA have independent predictive accuracy with regard to postoperative complications [14]. In a subsequent study, the authors further detected that the SNAQ and MUST have comparable accuracy in detecting malnutrition. Nevertheless, the authors acknowledge that whether preoperative nutritional therapy would improve the outcome in malnourished patients needs to be studied [13]. In fact, no validated presurgical scoring system is available to identify patients at an early enough time point for preoperative nutritional replenishment.

\section{Postoperative nutrition risk assessment to identify patients who may benefit from nutrition therapy}

As the aforementioned tools consider all critically ill patients at high risk for malnutrition, the Nutrition Risk in the Critically ill (NUTRIC) score was developed to define nutrition risk in the critically ill ICU patients 


\begin{tabular}{|c|c|c|c|c|c|c|}
\hline & \multirow{2}{*}{ pre hospital phase } & \multicolumn{3}{|c|}{ in hospital } & \multirow{2}{*}{ following discharge } & \multirow{2}{*}{ Impacted Outcomes } \\
\hline & & preoperative phase & surgery & postoperative care & & \\
\hline 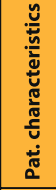 & $\begin{array}{l}\text { Comorbidities } \\
\text { Medications } \\
\text { Demographics } \\
\text { Age } \\
\text { Functional status } \\
\text { Frailty }\end{array}$ & $\begin{array}{l}\text { hemodynamic } \\
\text { instability }\end{array}$ & $\begin{array}{l}\text { Cardiac Surgical } \\
\text { Procedure } \\
\text { cardiopulmonary } \\
\text { bypass } \\
\text { hemodynamic } \\
\text { instability }\end{array}$ & $\begin{array}{l}\text { hemodynamic } \\
\text { instability }\end{array}$ & $\begin{array}{l}\text { hemodynamic } \\
\text { instability }\end{array}$ & $\begin{array}{l}28 \text { day mortality } \\
\text { Ventilator Free Days } \\
\text { quality of life } \\
\text { physical recovery } \\
\text { ( } 6 \text { min walk test) }\end{array}$ \\
\hline 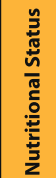 & $\begin{array}{l}\text { Chronic starvation } \\
\text { Weight loss over the last } 6 \\
\text { month } \\
\text { BMI }<20\end{array}$ & $\begin{array}{l}\text { Acute Starvation } \\
\text { Pre ICU Hospital Admission } \\
\text { Decreased preoperative } \\
\text { oral intake / } \\
\text { preoperative fasting } \\
\text { rescheduled surgery }\end{array}$ & & & muscle mass & $\begin{array}{l}\text { Micronutrient deficiency } \\
\text { Erosion of Lean Body Mass } \\
\text { Immune Dysfunction }\end{array}$ \\
\hline ๗ัँ & $\begin{array}{l}\text { Euroscore } \\
\text { Syntax } \\
\text { STS }\end{array}$ & & & $\begin{array}{l}\text { APACHE II } \\
\text { SOFA } \\
\text { Nutric, NRS }\end{array}$ & & \\
\hline 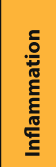 & $\begin{array}{l}\text { Chronic } \\
\text { inflammation } \\
\text { Co-morbid illnesses }\end{array}$ & & $\begin{array}{l}\text { Acute inflammation } \\
\text { IL-6 } \\
\text { PCT } \\
\text { and CRP }\end{array}$ & $\begin{array}{l}\text { Chronic } \\
\text { inflammation } \\
\text { prolonged ICU stay } \\
\text { postoperative } \\
\text { complications }\end{array}$ & & \\
\hline 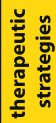 & oral supplementation & $\begin{array}{l}\text { nutritional boost } \\
\text { (e.g. carbohydrate solutions, } \\
\text { n-3 PUFA, selenium ...) }\end{array}$ & $\begin{array}{l}\text { nutritional boost } \\
\text { (e.g. } n-3 \text { PUFA, selenium) }\end{array}$ & $\begin{array}{l}\text { enteral and } \\
\text { parenteral nutrition } \\
\text { physiotherapy }\end{array}$ & & \\
\hline
\end{tabular}

Fig. 1 Organizing framework malnutrition and undernutrition and impact on outcomes in cardiac surgery patients. The patients' preoperative, intraoperative and postoperative time windows comprise specific variables, which may be of particular relevance for potential nutrition support and patients' outcomes after surgery. Notably, additional studies are encouraged to identify further relevant factors and to validate its clinical significance. STS Society of Thoracic Surgeons, BMI body mass index, ICU intensive care unit, APACHE II Acute Physiology And Chronic Health Evaluation II, SOFA sequential organ failure assessment, Nutric Nutrition Risk in the Critically ill, CRP C reactive protein, IL interleukin, PCT procalcitonin, PUFA polyunsaturated fatty acids, SYNTAX scoring system to guide decision between coronary artery bypass graft (CABG) surgery or percutaneous intervention (PCD), NRS nutritional risk score

[17-19]. The observation that not all ICU patients will respond the same to nutritional interventions was the critical driver for the development of the NUTRIC score $[17,20]$. Yet, the NUTRIC score has not yet been validated in cardiac surgery patients.

Considering the critically ill, the Nutritional Risk Score (NRS)-2002 must be interpreted cautiously as an Acute Physiology and Chronic Health Evaluation (APACHE) score $>10$ in cardiac surgery patients indicates that a patient is already at high risk for malnutrition. Patients with an NRS-2002 score $>3$ are defined as at "risk for malnutrition", and those with an NRS-2002 score $\geq 5$ as "high risk for malnutrition", which may be too broad and nonspecific for directing aggressive nutrition support. In contrast, the NUTRIC score was demonstrated in five prospective, but non-randomized studies, as a sensitive measure to identify the nutritional risk and to discriminate between patients with high risk for malnutrition and those likely to benefit from aggressive nutrition therapy [21]. Additionally, nutritional assessment by the NUTRIC score identified patients with a low nutrition risk in whom additional nutritional therapy may have neutral or negative effects.
The importance of this is evident in the EDEN trial, which compared the effects of early trophic feeds to early full enteral nutrition (EN) [22]. No difference was shown between trophic vs full feeds in terms of ventilator-free days, infections, or 60-day mortality rate. However, this study was performed in a rather young, initially well-nourished, and nutritional-insensitive patient population with a low NUTRIC score [22]. Casaer et al. [23] compared those with inadequate intake (caloric restriction) to early supplemental parental nutrition (PN) with prior glucose loading. Early initiation of PN to supplement insufficient EN was associated with a higher incidence of infections, delayed recovery, and higher health care costs compared with late initiation of PN. Again, this may have been the wrong target population as the majority of study patients had a short ICU stay, suggestive of a low nutrition risk. Furthermore, tight glycemic control and high-dose glucose loading may have negatively affected the results. It is unlikely that patients having cardiac surgery and at low nutrition risk would benefit from aggressive, early PN, therefore enrolment of these patients in a large clinical trial would be nonsensical. An adequate risk assessment 
is mandatory to first identify high-risk patients for cardiac surgery before scientifically studying nutrition support implementation.

\section{Further nutrition assessments tools in cardiac surgery}

Ultrasound of the quadriceps muscle is an easy-to-use and readily available tool to measure muscle mass and determine changes in muscle and fat tissue [24-26]. Computed tomography (CT) is also a well-established body composition analysis tool, though more expensive, not risk-free, and difficult to access $[25,26]$. Recently, the validity of bioelectrical impedance spectroscopy (BIS) that calculates fat-free mass from measurements of body water has shown promising results in determining nutritional reserve in cardiac patients [27]. In that study a preoperative low bioelectrical impedance phase was associated with malnutrition and increased risk of adverse postoperative events [27]. Yet, the high fluid intake may significantly influence the reliability of BIS. Considering clinical practicability, both CT scan and BIS may open the opportunity for preoperative and postoperative nutrition assessment in cardiac surgery patients. In summary, biochemical inflammatory markers are unlikely to be of use. Ultrasound, CT, and BIS may represent promising future tools allowing quantitative assessment of body composition and, therefore, nutritional status.

\section{Optimal time point for perioperative nutrition therapy in cardiac surgery patients}

Determining the ideal time to start feeding in relation to cardiac surgery represents a crucial factor for nutritional support to be effective. Until now, only a few studies have addressed this question. In regards to timing, the following time windows may be of particular relevance:

- Preoperative: at least 2-7 days before surgery

- Early preoperative: $\leq 24$ hours before surgery

- Early postoperative: $\leq 24$ hours after ICU admission

- Postoperative: $>24$ hours after ICU admission

One challenging aspect facing perioperative nutritional support is the fact that over half the patients having cardiac surgery are admitted as outpatients on the day of surgery, creating a significant challenge to preoperative nutritional risk assessment and timely intervention. If a beneficial role for a preoperative approach is determined, clinicians will need to overcome this challenge and consider an outpatient approach to optimize the nutritional status prior to admission. In the meantime, the best assessment and treatment window for now is immediately after surgery or soon after arrival at the ICU. Due to the limited evidence on the preoperative or early postoperative identification of these patients, current practice currently only allows practitioners to initiate the nutrition therapy on an individualized patient-tailored consideration.

\section{Enteral vs parenteral nutrition in cardiac surgery patients}

Considering international guidelines, there is a strong consensus and most experts will report that EN is always preferred to PN. Following cardiac surgery, critically ill patients are frequently on vasopressor treatment because of an inflammatory response syndrome, vasoplegia, and/or postoperative low output syndrome due to myocardial stunning. The need for vasopressor support further results in marked changes in energy expenditure and frequent intolerance to oral feeding, leading to significant energy/protein deficits and increased risk of malnutrition. Although proven safe [28], EN is often thought to be contraindicated and considered as harmful especially in hemodynamically unstable patients on large doses of inotropes and/or vasopressors, leading to a widespread use of $\mathrm{PN}$ in clinical practice. Berger et al. were among the first to provide evidence from a small cohort on the feasibility and safety of early nutrition support in patients after cardiac surgery. Using a well-established paracetamol absorption test, the investigators demonstrated that hypocaloric EN was feasible in such patients with altered hemodynamic status [28]. Kahlid et al. demonstrated in a large scale, multi-center, observational study that mechanically ventilated, vasopressor-dependent patients (mixed population) had a significant survival advantage when EN feeding was started within the first 48 hours after ICU admission, compared to those receiving EN feeding later than 48 hours [29]. Furthermore, in a subgroup analysis, they demonstrated that the sickest patients (on multiple vasopressors compared to those on one vasopressor only) had a more pronounced survival advantage. In addition, nutrition support was demonstrated to be feasible in patients with extracorporeal life support systems (ECLS). All patients on ECLS (in venovenous or venoarterial mode) were fed using existing protocols that emphasize early EN in preference over PN or delayed EN [30]. Notably, the use of paralysis and sedation did not affect feeding tolerance regarding the time to reach goal rate, incidence of intolerance in the first 5 days, or time until first observed bowel motion. In contrast, actual guidelines recommend withholding EN nutrition in hemodynamically unstable patients, though this is primarily based on preclinical and observational studies [31]. The rationale behind this is that the hemodynamic failure may compromise the splanchnic blood flow, causing intestinal ischemia [32], which is associated with high mortality [33, 34]. 
Given the current evidence, vasopressor use per se is not a contraindication to EN. In hemodynamically unstable critically ill or cardiac surgery patients, there is at least some evidence that early EN is absorbed and metabolized without any harmful effect on systemic measurements of oxygenation and perfusion and supportive evidence from a large-scale observational study that this translates into an advantage in terms of mortality [28]. Therefore, early EN may be beneficial in patients after initial resuscitation from critical organ failure. Future well-designed studies are needed for an adequate assessment of this important question.

\section{Counteracting the inflammatory response - the role of key nutrients}

Cardiac surgery with myocardial ischemia/reperfusion and use of CPB is known to be associated with deleterious consequences, resulting from the inflammatory response during cardiac surgery. The duration of $\mathrm{CPB}$ time correlates with the extent of the inflammatory response. Furthermore, surgical trauma, ischemia/reperfusion, and contact activation with the $\mathrm{CPB}$ circuit result in the release of mainly pro-inflammatory markers, reactive oxygen species, and reactive nitrogen species that contribute to the development of organ dysfunction [35]. In this setting, the use of pharmaco-nutrients, which may exert specific effects on metabolism, the inflammatory response, markers of oxidative stress, and immune cell activity, are of considerable interest. The amino acids glutamine and arginine, lipids such as omega-3 fatty acids, micronutrients such as selenium and zinc, or vitamins $\mathrm{A}, \mathrm{C}, \mathrm{D}$, and $\mathrm{E}$, are examples of such key nutrients. Despite theoretical promise, several large-scale clinical trials involving these nutrients had disappointing results in the general ICU patient population [22, 36-38]. However, in a small randomized trial in 177 patients, Leong et al. demonstrated that perioperative metabolic therapy with coenzyme Q10, magnesium, lipoic acid, omega-3 fatty acids, and selenium was feasible, safe, and associated with improved redox status, reduced myocardial damage, and shorter length of postoperative hospital stay after cardiac surgery [39]. Although by no means generalizable, the results of that study support the hypothesis that key nutrients can mitigate perioperative oxidative stress and improve cardiac surgical outcomes. Similarly, recent results from a nonrandomized open-label study indicate a beneficial effect of perioperative sodium selenite supplementation, whereas the supplementation strategy was still insufficient to compensate for a second decrease in selenium levels during the postoperative course. Given these data, a large-scale multi-center trial was recently launched to study the clinical significance of high-dose $(2000 \mu \mathrm{g})$ perioperative sodium selenite supplementation in patients at high risk after cardiac surgery [40].

In a recent clinical trial, perioperative nutritional therapy was administered in the cardiac surgery ICU in order to increase myocardial and plasma arginine/ asymmetric dimethylarginine ratio and other amino acids [41]. The investigators demonstrated an increase in inflammatory cells in cardiac tissue at the start and end of cardiac surgery, whereas perioperative supplementation during surgery did not affect the myocardial inflammatory response [41]. Similarly, Tepaske et al. performed a double-blind, three-arm clinical trial to determine whether the addition of glycine to oral nutrition may improve the patients' outcomes after cardiac surgery. It was demonstrated that oral immune-enhancing nutrition reduced postoperative complications, whereas the addition of glycine did not result in any additional beneficial effect [42]. Taken together, recent data do not show a clinical relevant benefit after supplementation of arginine or glycine in patients undergoing cardiac surgery.

So far, preliminary results from small phase II trials on fish oil (FO)-containing emulsions have demonstrated that preoperative FO application is a promising strategy to modulate the biological and clinical response to cardiac surgery [43]. Berger et al. demonstrated that perioperative FO infusions significantly decreased biological and clinical signs of inflammation, in a rather low-risk population of cardiac surgery patients, as reflected by a low mean Euroscore (5), which is routinely used for the preoperative risk stratification in cardiac surgery patients. Furthermore, mainly uncomplicated coronary artery bypass surgery was performed [44]. Given these findings, supplementation of FO may be of particular relevance in patients with more complex procedures with more prolonged $\mathrm{CPB}$ time and subsequent pronounced inflammatory response. Manzanares et al. recently conducted a systematic review and included 10 randomized controlled trials (RCTs), in which researchers evaluated FOcontaining emulsions in $\mathrm{PN}$ or EN in the ICU. The researchers found that FO-containing emulsions may significantly reduce the rate of infections. In addition, FO-containing emulsions were associated with clinically important reductions in duration of mechanical ventilation and hospital length of stay [45]. Further research is encouraged and is needed in cardiac surgery patients to clarify the role of FO.

Pharmaco-nutrition offers a promising approach to enhance the body's defense mechanisms and to attenuate the deleterious effects of SIRS and improve outcomes. This may be of particular relevance for high-risk patients undergoing complex procedures with prolonged CPB duration and an overwhelming release of pro-inflammatory mediators. 


\section{Main open research topics concerning nutrition in patients after cardiac surgery}

The few randomized trials of nutrition support in patients undergoing cardiac surgery are limited to small numbers of patients and demonstrate heterogeneous results, so the experts felt unable to give strong recommendations for clinical practice. Nevertheless, six key messages have been identified by the experts, which are thought to be of clinical relevance in the treatment of these patients:

1. Whenever possible, preoperative optimization of the nutritional state should be targeted in the malnourished patient undergoing cardiac surgery. The increasing number of patients with advanced heart failure and planned VAD implant represent a subpopulation that may as well benefit from optimization of the nutritional state. Thus, determination of nutritional risk, preferably using a structured scoring tool, should be part of the patient's preoperative assessment.

2. To reach maximum benefit, preoperative nutritional therapy should be initiated in malnourished patients after cardiac surgery at least 2-7 days before surgery (e.g., as part of a preoperative evaluation and optimization therapy) [46].

3. Monitoring of nutrition intake should be routinely assessed daily in patients after cardiac surgery during the ICU stay. In particular, on day 3 all patients should be carefully evaluated as to their nutrition risk and effort should be made to achieve at least $80 \%$ of their prescribed protein/energy requirements, either by enteral or parental feeding, as soon as possible.

4. Postoperative nutrition support should be initiated early (0-24 hours after surgery) in patients at high nutritional risk with an expected prolonged ICU stay.

5. Attention to refeeding syndrome may be of importance for patients in whom nutrition support is started after a prolonged period of starvation or in patients with preexisting malnutrition, respectively. In those patients, advancement of feeding should be slower, taking 3-4 days to reach goal, and targeting to adapt to both macronutient and micronutrient special needs [31].

6. If initiated early postoperatively within $<24$ hours after ICU admission, an additional immunemodulating component (e.g., selenium, fish oil) to nutrition may be considered for patients with complex and prolonged surgical procedures, to counteract the overwhelming inflammatory response.

In extension to the need of reliable data, international standardized procedures such as the ESPEN and IASMEN endorsed strategy for Enhanced Recovery After Surgery
(ERAS) are warranted to optimize nutrition support in cardiac surgery patients. In view of the heterogeneous standards of perioperative care in these patients and lack of evidence provided by large-scale RCTs, the multimodal ERAS program for optimal perioperative care may help to reduce surgical stress, maintain physiological functional capacity, and facilitate postoperative recovery by providing the best available evidence [47].

Furthermore the multidisciplinary group identified six important topics for future research:

1. Targeting preoperative optimization of the nutritional state may result in improved postoperative outcome. Structured scoring tools should be validated and implemented as part of preoperative assessment and to monitor the efficacy of nutrition therapy.

2. In identified patients, the feasibility and clinical significance of early-initiated postoperative nutrition support needs to be evaluated.

3. Dose-finding studies for both macronutrients and micronutrients are needed to answer the questions of "how to supplement patients after cardiac surgery" and "with which combination of nutrients".

4. To counteract the frequently occurring inflammatory response, the clinical significance of an immune-modulating component (e.g., selenium, fish oil) should be evaluated in patients with complex and prolonged surgical procedures.

5. Validated and reliable assessment of energy requirement in patients after cardiac surgery need to be developed.

6. The role trophic EN might play in the hemodynamically stable patient after initial stabilization needs further evaluation.

\section{Conclusion}

Valid and reliable data are urgently needed to improve the so far non-standardized clinical practice of nutrition screening, assessment, and support in patients after cardiac surgery. Although both inflammatory response and postoperative complications are predictable, clinical practice has several restrictions, limiting optimal nutrition therapy. The accurate identification of patients who benefit most from nutritional therapy presents a clinical imperative requiring validation by adequately powered clinical studies.

\section{Abbreviations}

BIS: Bioelectrical impedance spectroscopy; CABG: Coronary artery bypass grafting; CPB: Cardiopulmonary bypass; CRP: C-reactive protein;

CT: Computed tomography; ECLS: Extracorporeal life support systems; EN: Enteral nutrition; FO: Fish oil; ICU: Intensive care unit; IL: Interleukin; MNA: Mini Nutritional Assessment; MST: Malnutrition Screening Tool; MUST: Malnutrition Universal Screening Tool; NRS: Nutritional risk score; NT: Nutritional therapy; NUTRIC: Nutrition Risk in the Critically ill; 
PCT: Procalcitonin; PN: Parenteral nutrition; RCT: randomized controlled trial RNS: Reactive nitrogen species; ROS: Reactive oxygen species: SGA: Subjective Global Assessment; SIRS: Systemic inflammatory response syndrome; SNAQ: Short Nutritional Assessment Questionnaire;

VAD: Ventricular assist device

\section{Acknowledgements}

We are thankful for the valuable comments and suggestions given by Dr. U. Brauer, Dr. E. v Kleist, K. Klütsch and W. Cetnarowski (B. Braun Melsungen AG (Melsungen, Germany)).

\section{Funding}

The 1st International Expert Meeting of Intensivists, Anaesthesiologists, Dieticians and Cardiac Surgeons in Boston was financially supported by B. Braun Melsungen AG (Melsungen, Germany). None of the authors have competing interests.

\section{Availability of data and materials}

Not applicable.

\section{Authors' contributions}

SC, GA, WG, OR, BT, HR, KA, MP, MJ, EA, YD, MDB, CM, JP, BR, TR, EG, LO, AR, $L V, N E, M G, B C, M L$, and $H D$ substantially contributed to the design and conception of this article. SC, GA, WG, OR, BT, HR, KA, MP, MJ, EA, YD, MDB, $C M, J P, B R, T R, E G, L O, A R, L V, N E, M G, B C, M L$, and $H D$ performed the analysis for the systematic review and drafted the manuscript. All authors read and approved the final manuscript.

\section{Authors' information}

Not applicable.

\section{Competing interest}

The authors declare that they have no competing interests.

\section{Consent for publication}

All authors confirmed consent for publication of the present manuscript.

\section{Ethics Approval and Consent to participate}

Not applicable.

\section{Publisher's Note}

Springer Nature remains neutral with regard to jurisdictional claims in published maps and institutional affiliations.

\section{Author details}

'Department of Intensive Care Medicine, University Hospital of the RWTH Aachen, Pauwelsstraße 30, 52074 Aachen, Germany. ${ }^{2}$ Department of Thoracic, Cardiac and Vascular Surgery, University Hospital, RWTH Aachen, Pauwelsstraße 30, 52074 Aachen, Germany. ${ }^{3}$ Cardiac Surgical Intensive Care, Johns Hopkins Hospital Baltimore, Blalock 618, 600 N. Wolfe Street, Baltimore, MD 21287, USA. ${ }^{4}$ Department of Anesthesia, Royal Victoria Hospital, McGill University Health Centre, Montreal, Canada. ${ }^{5}$ Department of Microbiology and Immunology, McGill University Health Centre, Montreal, Canada. ${ }^{6}$ Department of Anaesthesiology, Intensive Care Medicine and Pain Therapy, University Hospital Frankfurt, Theodor-Stern-Kai 7, 60590 Frankfurt am Main, Germany. ${ }^{7}$ Division of Endocrinology, Diabetes, and Bone Disease, Icahn School of Medicine at Mount Sinai, New York, NY, USA. ${ }^{8}$ cahn School of Medicine at Mount Sinai, New York, NY, USA. ${ }^{9}$ Department of Surgery, Division of Trauma, Emergency Surgery and Surgical Critical Care, Massachusetts General Hospital, Boston, MA, USA. ${ }^{10}$ Division of Cardiac Anesthesiology and Critical Care Medicine, University of Ottawa Heart Institute, Ruskin Street H2410, Ottawa, ON K1Y 4W7, Canada. ${ }^{11}$ Department of Medicine, Aristotle University of Thessaloniki, University Campus, Thessaloniki 54124, Greece. ${ }^{12}$ Departments of Anesthesia \& Perioperative Medicine and Epidemiology \& Biostatistics, University of Western Ontario, London, Canada. ${ }^{13}$ Department of Surgery, University of Utah School of Medicine, Salt Lake City, UT, USA. ${ }^{14}$ Department of Anesthesiology, The Ohio State University College of Medicine, Columbus, OH, USA. ${ }^{15}$ Department of Anesthesiology and Intensive Care Medicine, University Medical Center Schleswig-Holstein, Campus Kiel, Arnold-Heller-Str 3 Haus 12, 24105 Kiel, Germany. ${ }^{16}$ Department of Cardiothoracic Surgery, Heart Center, University of
Cologne, Cologne, Germany. ${ }^{17}$ Department of Anesthesiology, Section on Critical Care Medicine, Wake Forest School of Medicine, Medical Center Boulevard, Winston-Salem, NC 27157, USA. ${ }^{18}$ Department of Anesthesiology and Intensive Care, Research Institute of Circulation Pathology, Novosibirsk, Russia. ${ }^{19}$ Department of Anesthesiology and Intensive Care Medicine, National Pirogov Surgical Medical Center, Moscow, Russia. ${ }^{20}$ Department of Critical Care Medicine, Queen's University and Clinical Evaluation Research Unit, Angada 4, Kingston General Hospital, Kingston, ON K7L 2V7, Canada.

Received: 22 December 2016 Accepted: 2 May 2017

Published online: 05 June 2017

\section{References}

1. Stoppe C, Meybohm P, Coburn M, Goetzenich A. Cardioprotection in cardiac surgical patients: everything good comes from the heart. Anaesthesist. 2016:65:169-82.

2. Kim B-S, Jacobs D, Emontzpohl C, Goetzenich A, Soppert J, Jarchow M, et al. Myocardial ischemia induces SDF-1a release in cardiac surgery patients. J Cardiovasc Transl Res. 2016;9:230.

3. Dreymueller D, Goetzenich A, Emontzpohl C, Soppert J, Ludwig A, Stoppe C. The perioperative time course and clinical significance of the chemokine CXCL16 in patients undergoing cardiac surgery. J Cell Mol Med. 2016;20:104-15.

4. Stoppe C, McDonald B, Benstoem C, Elke G, Meybohm P, Whitlock R, et al. Evaluation of persistent organ dysfunction plus death as a novel composite outcome in cardiac surgical patients. J Cardiothorac Vasc Anesth. 2016:30:30-8.

5. Drover JW, Cahill NE, Kutsogiannis J, Pagliarello G, Wischmeyer P, Wang M, et al. Nutrition therapy for the critically ill surgical patient: we need to do better! JPEN. 2010;34:644-52.

6. Rahman A, Hasan RM, Agarwala R, Martin C, Day AG, Heyland DK. Identifying critically-ill patients who will benefit most from nutritional therapy: further validation of the "modified NUTRIC" nutritional risk assessment tool. Clin Nutr. 2016:35:158-62.

7. Jakob SM, Stanga Z. Perioperative metabolic changes in patients undergoing cardiac surgery. Nutrition. 2010;26:349-53.

8. Ljungqvist O, Søreide E. Preoperative fasting. Br J Surg. 2003;90:400-6.

9. Bengmark $\mathrm{S}$. Jejunal feeding in severe pancreatitis and peritonitis. Nutrition. 2001;17:156-7.

10. Alexander JH. Smith PK. Coronary-artery bypass grafting. N Engl J Med. 2016;374:1954-64

11. Chermesh I, Hajos J, Mashiach T, Bozhko M, Shani L, Nir R-R, et al. Malnutrition in cardiac surgery: food for thought. Eur J Prev Cardiol. 2014:21:475-83.

12. Sanchez JA, Sanchez LL, Dudrick SJ. Nutritional considerations in adult cardiothoracic surgical patients. Surg Clin North Am. 2011;91:857-75. ix.

13. Lomivorotov W, Efremov SM, Boboshko VA, Nikolaev DA, Vedernikov PE, Lomivorotov VN, et al. Evaluation of nutritional screening tools for patients scheduled for cardiac surgery. Nutrition. 2013:29:436-42.

14. Lomivorotov W, Efremov SM, Boboshko VA, Nikolaev DA, Vedernikov PE, Deryagin MN, et al. Prognostic value of nutritional screening tools for patients scheduled for cardiac surgery. Interact Cardiovasc Thorac Surg. 2013;16:612-8

15. Tepaske R, Velthuis H, Oudemans-van Straaten HM, Heisterkamp SH, van Deventer SJ, Ince C, et al. Effect of preoperative oral immune-enhancing nutritional supplement on patients at high risk of infection after cardiac surgery: a randomised placebo-controlled trial. Lancet. 2001;358:696-701.

16. Anthony PS. Nutrition screening tools for hospitalized patients. Nutr Clin Pract. 2008:23:373-82

17. Heyland DK, Dhaliwal R, Jiang X, Day AG. Identifying critically ill patients who benefit the most from nutrition therapy: the development and initial validation of a novel risk assessment tool. Crit Care. 2011:15:R268.

18. Korfali G, Gündoğdu H, Aydintuğ S, Bahar M, Besler T, Moral AR, et al. Nutritional risk of hospitalized patients in Turkey. Clin Nutr. 2009:28:533-7.

19. Kondrup J, Rasmussen HH, Hamberg O, Stanga Z, Ad Hoc ESPEN Working Group. Nutritional risk screening (NRS 2002): a new method based on an analysis of controlled clinical trials. Clin Nutr. 2003;22:321-36.

20. Jensen GL, Mirtallo I, Compher C, Dhaliwal R, Forbes A, Grijalba RF, et al. Adult starvation and disease-related malnutrition: a proposal for etiologybased diagnosis in the clinical practice setting from the International Consensus Guideline Committee. JPEN. 2010;34(2):156-9. 
21. Heyland DK, Dhaliwal R, Wang M, Day AG. The prevalence of iatrogenic underfeeding in the nutritionally "at-risk" critically ill patient: results of an international, multicenter, prospective study. Clin Nutr. 2015;34:659-66.

22. National Heart, Lung, and Blood Institute Acute Respiratory Distress Syndrome (ARDS) Clinical Trials Network, Rice TW, Wheeler AP, Thompson BT, Steingrub J, Hite RD, Moss M, Morris A, Dong N, Rock P. Initial trophic vs full enteral feeding in patients with acute lung injury: the EDEN randomized trial. JAMA. 2012;307:795-803.

23. Casaer MP, Mesotten D, Hermans G, Wouters PJ, Schetz M, Meyfroidt G, et al. Early versus late parenteral nutrition in critically ill adults. N Engl J Med. 2011;365:506-17.

24. Tillquist M, Kutsogiannis DJ, Wischmeyer PE, Kummerlen C, Leung R, Stollery $D$, et al. Bedside ultrasound is a practical and reliable measurement tool for assessing quadriceps muscle layer thickness. JPEN. 2014;38:886-90.

25. Baracos V, Kazemi-Bajestani SMR. Clinical outcomes related to muscle mass in humans with cancer and catabolic illnesses. Int J Biochem Cell Biol. 2013; 45:2302-8.

26. Puthucheary ZA, Rawal J, McPhail M, Connolly B, Ratnayake G, Chan P, et al. Acute skeletal muscle wasting in critical illness. JAMA. 2013;310:1591-600.

27. Visser M, van Venrooij LMW, Wanders DCM, de Vos R, Wisselink W, van Leeuwen PAM, et al. The bioelectrical impedance phase angle as an indicator of undernutrition and adverse clinical outcome in cardiac surgical patients. Clin Nutr. 2012;31:981-6.

28. Berger MM, Berger-Gryllaki M, Wiesel PH, Revelly JP, Hurni M, Cayeux C, et al. Intestinal absorption in patients after cardiac surgery. Crit Care Med. 2000;28:2217-23.

29. Khalid I, Doshi P, DiGiovine B. Early enteral nutrition and outcomes of critically ill patients treated with vasopressors and mechanical ventilation. Am J Crit Care. 2010;19:261-8.

30. Ferrie $S$, Herkes R, Forrest P. Nutrition support during extracorporeal membrane oxygenation (ECMO) in adults: a retrospective audit of 86 patients. Intensive Care Med. 2013:39:1989-94.

31. McClave SA, Taylor BE, Martindale RG, Warren MM, Johnson DR, Braunschweig C, et al. Guidelines for the provision and assessment of nutrition support therapy in the adult critically ill patient: Society of Critical Care Medicine (SCCM) and American Society for Parenteral and Enteral Nutrition (ASPEN). JPEN. 2016:40:159-211.

32. Jakob SM. Splanchnic blood flow in low-flow states. Anesth Analg. 2003;96: 1129-38.

33. Lazar HL, Fitzgerald C, Gross S, Heeren T, Aldea GS, Shemin RJ. Determinants of length of stay after coronary artery bypass graft surgery. Circulation. 1995; 92:1120-4.

34. Venkateswaran RV, Charman SC, Goddard M, Large SR. Lethal mesenteric ischaemia after cardiopulmonary bypass: a common complication? Eur J Cardiothorac Surg. 2002;22:534-8.

35. Hall R. Identification of inflammatory mediators and their modulation by strategies for the management of the systemic inflammatory response during cardiac surgery. J Cardiothorac Vasc Anesth. 2013;27:983-1033.

36. Heyland D, Muscedere J, Wischmeyer PE, Cook D, Jones G, Albert M, et al. A randomized trial of glutamine and antioxidants in critically ill patients. N Engl J Med. 2013;368:1489-97.

37. van Zanten ARH, Sztark F, Kaisers UX, Zielmann S, Felbinger TW, Sablotzki $A R$, et al. High-protein enteral nutrition enriched with immune-modulating nutrients vs standard high-protein enteral nutrition and nosocomial infections in the ICU: a randomized clinical trial. JAMA. 2014:312:514-24.

38. Bloos F, Trips E, Nierhaus A, Briegel J, Heyland DK, Jaschinski U, et al. Effect of sodium selenite administration and procalcitonin-quided therapy on mortality in patients with severe sepsis or septic shock: a randomized clinical trial. JAMA Intern Med. 2016;176:1266-76.

39. Leong J-Y, van der Merwe J, Pepe S, Bailey M, Perkins A, Lymbury R, et al. Perioperative metabolic therapy improves redox status and outcomes in cardiac surgery patients: a randomised trial. Heart Lung Circ. 2010;19:584-91.

40. Stoppe C, McDonald B, Rex S, Manzanares W, Whitlock R, Fremes S, et al Sodium selenite administration in cardiac surgery (SUSTAIN CSX-trial): study design of an international multicenter randomized double-blinded controlled trial of high dose sodium-selenite administration in high-risk cardiac surgical patients. Trials. 2014;15:339.

41. Visser M, Niessen HWM, Kok WEM, Cocchieri R, Wisselink W, van Leeuwen PAM, et al. Nutrition before and during surgery and the inflammatory response of the heart: a randomized controlled trial. J Nutr Metab. 2015 2015:123158-8.
42. Tepaske R, te Velthuis $H$, Oudemans-van Straaten HM, Bossuyt PMM, Schultz MJ, Eijsman L, et al. Glycine does not add to the beneficial effects of perioperative oral immune-enhancing nutrition supplements in highrisk cardiac surgery patients. JPEN. 2007:31:173-80.

43. Heidt MC, Vician M, Stracke SKH, Stadlbauer T, Grebe MT, Boening A, et al. Beneficial effects of intravenously administered N-3 fatty acids for the prevention of atrial fibrillation after coronary artery bypass surgery: a prospective randomized study. Thorac Cardiovasc Surg. 2009;57:276-80.

44. Berger MM, Delodder F, Liaudet L, Tozzi P, Schlaepfer J, Chioléro RL, et al. Three short perioperative infusions of $n-3$ PUFAs reduce systemic inflammation induced by cardiopulmonary bypass surgery: a randomized controlled trial. Am J Clin Nutr. 2013;97:246-54.

45. Manzanares W, Langlois PL, Dhaliwal R, Lemieux M, Heyland DK. Intravenous fish oil lipid emulsions in critically ill patients: an updated systematic review and meta-analysis. Crit Care. 2015:19:167.

46. Gillis C, Carli F. Promoting perioperative metabolic and nutritional care. Anesthesiology. 2015:123:1455-72.

47. Gustafsson UO, Scott MJ, Schwenk W, Demartines N, Roulin D, Francis N, et al. Guidelines for perioperative care in elective colonic surgery: Enhanced Recovery After Surgery $\left(\operatorname{ERAS}\left({ }^{\circledR}\right)\right)$ Society recommendations. World J Surg. 2013:259-84.

48. Rahman A, Agarwala R, Martin C, Nagpal D, Teitelbaum M, Heyland DK. Nutrition therapy in critically ill patients following cardiac surgery: defining and improving practice. JPEN. 2016.

49. Flordelís Lasierra JL, Pérez-Vela JL, Umezawa Makikado LD, Torres Sánchez E, Colino Gómez L, Maroto Rodríguez B, et al. Early enteral nutrition in patients with hemodynamic failure following cardiac surgery. JPEN. 2015;39(2):154-62.

50. Visser M, Davids M, Verberne HJ, Kok WE, Tepaske R, Cocchieri R, et al. Nutrition before, during, and after surgery increases the arginine: asymmetric dimethylarginine ratio and relates to improved myocardial glucose metabolism: a randomized controlled trial. Am J Clin Nutr. 2014 99(6):1440.

51. Umezawa Makikado LD, Flordelís Lasierra JL, Pérez-Vela JL, Colino Gómez L, Torres Sánchez E, Maroto Rodríguez B, et al. Early enteral nutrition in adults receiving venoarterial extracorporeal membrane oxygenation: an observational case series. JPEN. 2013;37(2):281-4.

52. Rapp-Kesek D, Joachimsson PO, Karlsson T. Splanchnic blood flow and oxygen consumption: effects of enteral nutrition and dopexamine in the elderly cardiac surgery patient. Acta Anaesthesiol Scand. 2007:51(5):570.

53. Berger MM, Berger MM, Revelly JP, Cayeux MC, Chiolero RL. Enteral nutrition in critically ill patients with severe hemodynamic failure after cardiopulmonary bypass. Clin Nutr. 2005;24(1):124-32.

54. Sustić A, Zelić M, Protić A, Zupan Z, Simić O, Desa K. Metoclopramide improves gastric but not gallbladder emptying in cardiac surgery patients with early intragastric enteral feeding: randomized controlled trial. Croat Med J. 2005;46(2):239.

55. Hartwell D, Henry J. Dietary advice for patients undergoing coronary artery bypass surgery: falling on deaf ears? Int J Food Sci Nutr. 2003; 54(1):37-47.

56. Kesek DR, Akerlind L, Karlsson T. Early enteral nutrition in the cardiothoracic intensive care unit. Clin Nutr. 2002;21(4):303-7.

57. Tepeske R, Velthuis H, Oudemans-van Straaten HM, Heisterkamp SH, Ince C, et al. Effect of preoperative oral immune-enhancing nutritional supplement on patients at high risk of infection after cardiac surgery: a randomised placebo-controlled trial. Lancet. 2001;358(9283):696-701.

58. Revelly JP, Tappy L, Berger MM, Gersbach P, Cayeux C, Chioléro R. Early metabolic and splanchnic responses to enteral nutrition in postoperative cardiac surgery patients with circulatory compromise. Intensive Care Med. 2001;27(3):540-7.

59. Fiaccadori E, Tortorella G, Gonzi G, Pincolini S, Belli L, Albertini D, et al, Hemodynamic, respiratory, and metabolic effects of medium-chain triglyceride-enriched lipid emulsions following valvular heart surgery. Chest. 1994;106(6):1660-7.

60. Behrendt W, Minale C, Giani G. Parenteral feeding following heart surgery operations. Infusionsther Klin Ernahr. 1984;11(6):316-22.

61. Weidler B, von Bormann B, Muhrer KH, Kothe M, Grimm E, Boldt J, et al. Effect of postoperative parenteral feeding on protein metabolism in heart surgery patients. A comparative study. Infusionsther Klin Ernahr. 1984;11(4): $235-41$. 
62. Haider W, Benzer H, Coraim F, Khosropour R, Mohl W, Müller M. Postoperative therapy by means of acute parenteral alimentation (APA) with high doses of insulin and glucose after open heart surgery. Der Anaesthesist. 1981;30(2):53.

63. Fisch D, Abel RM. Hemodynamic effects of intravenous fat emulsions in patients with heart disease. JPEN. 1981;5(5):402-5.

64. Abel RM, Fischer JE, Buckley MJ, Barnett GO, Austen GW. Malnutrition in cardiac patients: results of a prospective, randomized evaluation of early postoperative total parenteral nutrition (TPN). Acta Chir Scand Suppl. 1976;466:77

Submit your next manuscript to BioMed Central and we will help you at every step:

- We accept pre-submission inquiries

- Our selector tool helps you to find the most relevant journal

- We provide round the clock customer support

- Convenient online submission

- Thorough peer review

- Inclusion in PubMed and all major indexing services

- Maximum visibility for your research

Submit your manuscript at www.biomedcentral.com/submit 